\title{
Dilución del poder y bien común
}

\section{Ramón Barinaga Osinalde}

\section{Gautena}

<direccion@gautena.org>
Gaur egungo krisi ekonomiko eta politikoak begien bistan jartzen du hiru faktoreen interakzioa. Batetik, boterearen transformazio historiko bat, eta zuzentzen ari da progresiboki diluitzera, modu horretan hazten delarik eskala agregatuan erabakiak hartzeko zailtasuna onura publiko kolektiboko gaietan -bakea, gosea, desberdintasuna, ingurumena-. Bestetik, politikarekiko hazten ari den gaitzustea, eta sistema demokratikoek bizi duten hiritargoaren konfiantza-galera. Azkenik, eskastasun edo prekarietatearen hazkundea, erantzuna eman beharreko arazo sozial eta politiko gisara. Hiru faktore horien baturatik premia eratorriko litzateke adostutako onura publikoaren ulermen berri batean aurrerabidea egiteko.

\section{GAKO-HITZAK:}

Boterea, onura publiko kolektiboak, eskastasuna, transformazio handia, guztien ongizatea.
La actual crisis económica y política estaría poniendo en evidencia la interacción de tres factores. Por un lado, una histórica transformación del poder, que apunta hacia su progresiva dilución, incrementándose así la dificultad para tomar decisiones a escala agregada respecto de los denominados bienes públicos colectivos -la paz, el hambre, la desigualdad, el medioambiente-. Por otro lado, la creciente desafección de la política, en la que los sistemas democráticos experimentan una pérdida de confianza de la ciudadanía. Por último, el incremento del precariado, como problema social y político al que hay que dar respuesta. De la conjunción de estos tres factores, se derivaría la necesidad de avanzar hacia una nueva comprensión acordada del bien común.

\section{PALABRAS CLAVE:}

Poder, bienes públicos colectivos, precariado, gran transformación, bien común. 


\section{Introducción}

En el transcurso de la crisis económica iniciada en 2007-2008 comienzan a identificarse, cada vez con mayor nitidez, algunas características de esta época en la que estamos viviendo. Según algunos autores, se estaría dando una histórica transformación del poder que conllevaría su paulatina dilución y, en consecuencia, una creciente dificultad para arbitrar respuestas a la consecución de bienes públicos globales -la paz en el mundo, el hambre, la desigualdad, el medioambiente-.

Ello ocurre en un momento en que, en las sociedades democráticas, se constata una creciente desafección por la política, habiéndose generado un problema de confianza sin precedentes en los propios mecanismos de representación e instituciones de las que se han dotado las sociedades más avanzadas, sin que los planteamientos para complementarlas con formas directas de participación hayan dado a luz todavía modelos ampliamente aceptados y operativos a escala agregada.

Al mismo tiempo, la crisis ha puesto de manifiesto la existencia de una suerte de nueva clase social, el precariado, identificada por un conjunto nuevo de características. La adecuada resolución de las necesidades de este amplio y heterogéneo colectivo es tarea urgente que compete a la política. No hacerlo plantea riesgos serios, toda vez que habría indicadores que mostrarían una tendencia de estos grupos sociales hacia fórmulas populistas o neofascistas, que, de prosperar, podrían poner en peligro el panorama institucional conocido y los equilibrios históricamente alcanzados entre política y economía.

Parece claro que, como sociedad, debemos avanzar hacia una nueva comprensión acordada del bien común. La realidad de la crisis sistémica en la que estamos -que algunos denominan 'gran transformación' (Trías de Bes, 2013)-, pone de manifiesto que los valores hoy imperantes en la economía no van a ser capaces de superar el actual estado de cosas, que ellos mismos han contribuido a generar, y que será necesario establecer nuevos acuerdos técnicos $\mathrm{y}$, finalmente, políticos, para avanzar hacia una nueva definición del bien común.

A partir de las diversas propuestas existentes -unas puramente economicistas, otras que abogan por la eficiencia para poder avanzar hacia una sociedad más humana, y otras que sugieren poner en pie de igualdad competencia y cooperación, equidad y reciprocidad, criticando el modelo imperante por basarse en la codicia, subrayando que la riqueza creciente de unos pocos no es el camino para el desarrollo de la mayoría y planteando nuevas vías hacia el bien común-, habrá que llegar a un acuerdo civilizado si no queremos encarar alternativas menos deseables.

El papel decreciente de los Estados-nación para enfrentar los grandes retos colectivos plantea el papel que pueden jugar entramados agregados como la Unión Europea. Los actuales problemas de gestión, orientación ideológica y pérdida de confianza de la ciudadanía de la Unión Europea constituyen dificultades objetivas que se han de resolver.

De la mano de diversos autores, desgranaremos los dos siguientes apartados, desde el análisis político y sociológico, y desde la economía, respectivamente, algunas de las cuestiones que han quedado esbozadas en esta introducción, para finalizar con un apartado de resumen y conclusiones.

\section{Perspectiva política y sociológica}

Moisés Naím, analista económico y político, doctor por el Massachusetts Institute of Technology (EE.UU.), plantea en su libro El fin del poder (2013) que éste, a pesar de seguir existiendo y ser muy poderoso, está cambiando y se está haciendo más difícil de ejercer, que en él intervienen más actores, que se incrementa la capacidad de bloqueo mutuo entre ellos, y todo ello, aun presentando aspectos positivos -como la desaparición de una o dos grandes superpotencias-, nos lleva a una creciente dificultad para tomar medidas de protección de los bienes públicos globales, como la desigualdad, el medioambiente o la paz en el mundo.

\subsection{La dilución del poder}

Para Moisés Naím, los cambios globales que estamos viendo en nuestros días, las por él denominadas “revoluciones del más" -más producción, más países, más bienes y servicios, más longevidad y, sobre todo, más personas-, "de la movilidad" -gente con vidas más plenas, que se mueve más-y “de la mentalidad" -crecimiento de una clase media en el que la gente ha mejorado su nivel de vida y vive en la "revolución de las expectativas crecientes"- han hecho que nuestros problemas sean más grandes y complejos, y al mismo tiempo, ha debilitado nuestros mecanismos para resolverlos" (ibídem: 90-104).

En opinión de este autor, “cada vez somos más incapaces de tomar medidas que vayan más allá del mínimo común denominador y supongan un paso hacia la solución del problema de que se trate. Contar en la mesa con un grupo de actores más variado e incluyente (los 'débiles' de otra época) y reducir el número de decisiones que unos cuantos podemos imponer arbitrariamente al resto del mundo es encomiable. Pero lograr resultados se ha vuelto mucho más difícil”. Para este politólogo, "el mensaje central es que la dilución excesiva del poder y la incapacidad de los principales actores de ejercer el liderazgo son tan peligrosas como la concentración del poder en unas pocas manos" (ibídem: 325-328).

Y continúa su argumentación del siguiente modo: "nuestro horizonte está abarrotado de graves amenazas, como la resolución de las crisis económicas, la proliferación nuclear, el cambio climático o la 
inseguridad cibernética, que no pueden resolverse si continúa declinando la capacidad de los países para ponerse de acuerdo y actuar colectivamente con eficacia. La degradación del poder está complicando aún más la posibilidad de responder a estas amenazas. La creciente debilidad de los actores dominantes y el crecimiento explosivo del número de participantes con algo de poder también están complicando la búsqueda de soluciones; ya no tenemos una o dos superpotencias que puedan imponer sus condiciones al resto del mundo. De nuevo: qué bueno que así sea y qué malo que aún no tengamos alternativas a la inacción que esto está produciendo" (ibídem: 329).

\subsection{Toma de decisiones y bienes públicos globales}

Para Naím, "las tareas colectivas como mantener la paz, impedir el terrorismo, responder a crisis económicas que se mueven de país en país, combatir epidemias, detener el cambio climático, rescatar Estados fallidos, luchar contra el blanqueo del dinero y los criminales transnacionales, y proteger las especies en peligro de extinción son bienes públicos globales. En otras palabras, son metas que, en caso de lograrse, benefician a toda la humanidad, incluidos quienes no han hecho nada para mitigar estas amenazas o paliar sus consecuencias" (ibídem: 330-331). En su opinión, “la degradación del poder agudiza el problema de la acción colectiva. Está sucediendo ya en el ámbito internacional con un número creciente de 'pequeños' países que vetan, exigen consideraciones especiales, logran que se pospongan las decisiones que no les convienen o las diluyen y, en general, obstaculizan los esfuerzos de las 'grandes' naciones en todos los terrenos. Y, mientras tanto, los países grandes ahora disponen de más maneras de bloquearse mutuamente". Y añade: "una respuesta que se ha intentado dar a la dificultad de la comunidad internacional para producir 'bienes públicos globales' a la velocidad y con la calidad necesarias es la creación de coaliciones de naciones" (ibídem: 331).

La degradación del poder genera riesgos que merman el bienestar social y la calidad de vida a corto plazo y, con el paso del tiempo, aumentan la probabilidad de un desastre climático o nuclear de primera magnitud. Hay cinco riesgos concretos que, en opinión de este analista, plantea la degradación del poder (ibídem: 332 y ss.):

- “El desorden": las revoluciones del más, de la movilidad y de la mentalidad han hecho que miles de millones de personas esperen más y exijan más, y tenemos mejores mecanismos para pedir responsabilidades.

- “La pérdida de talento y conocimiento": la posibilidad de que los partidos políticos sean sustituidos por 'movimientos' ad hoc, coaliciones electorales temporales o incluso organizaciones no gubernamentales centradas en un solo asunto (los 'verdes', 'piratas', 'antigobierno') resulta atractiva para los millones de votantes que están hartos de la corrupción, el estancamiento ideoló- gico y del decepcionante ejercicio de gobierno de muchos partidos políticos. Sin embargo, explica Naím, muchas veces son sustituidos por lo que el historiador suizo Jacob Burckhardt llamó "terribles simplificadores", demagogos que buscan obtener el poder a base de explotar la ira y la frustración de la población, y mediante promesas atractivas pero "terriblemente simples" $y$, en definitiva, “engañosas”.

- "La banalización de los movimientos sociales": las causas sociales y políticas tiene hoy 'seguidores' que pinchan el botón de 'me gusta' en el éter de los medios digitales. Para la mayoría de la gente, el activismo social o político en la red consiste en poco más que tocar un botón y, ocasionalmente, hacer una pequeña donación. No está mal, pero no es el activismo arriesgado que ha impulsado los grandes movimientos sociales de la historia.

- "Se estimula la impaciencia y se acortan los períodos de atención": aunque contar con millones de activistas en la red eleva la visibilidad social de miles de problemas, también crea un nivel de ‘ruido' y distracción que hace muy difícil que una causa retenga la atención y el apoyo popular durante el tiempo suficiente para adquirir una fuerza sustancial y permanente.

- “Alienación”: se corre el riesgo de caer en la anomía, la ruptura de los lazos sociales entre un individuo y la comunidad. El bombardeo tecnológico, el estallido de la comunicación digital, la distracción y el ruido de Internet, el fin de la aceptación automática de las autoridades tradicionales o el incremento de la soledad, ¿qué consecuencias pueden traer?

En definitiva, para Moisés Maím, si existe un riesgo creciente para las democracias y las sociedades liberales en el siglo XXI, lo más probable es que proceda del interior de las sociedades en las que se ha instalado la alienación. Como ejemplos, cita el auge de los movimientos que expresan o aprovechan la indignación social, desde los nuevos partidos de extrema derecha y extrema izquierda en Europa y Rusia, hasta el movimiento del Tea Party en Estados Unidos. Todos ellos son, para este autor, una manifestación de la degradación del poder, y la rabia incipiente que expresan se debe, en gran parte, a la alienación producida por la caída de los indicadores del orden y la seguridad económica. "Todo ello revela hasta qué punto la degradación del poder, si no nos adaptamos a ella y la orientamos hacia el bien social, puede acabar siendo contraproducente y destructiva”, concluye (ibídem: 338).

\subsection{El poder opaco y el cuestionamiento del orden político e institucional}

Desde una perspectiva sociológica, en su libro LoS poderes opacos: austeridad y resistencia (2013), Enrique Gil Calvo plantea algunas de las debilidades de mayor actualidad de los sistemas democráticos. 
Este autor clasifica las democracias en dos grandes grupos: "las más antiguas e institucionalizadas, que cumplen todos los requisitos de calidad democrática, en especial el imperio de la ley, la separación de poderes y la accountability o rendición de cuentas"; y por otro lado, "las más recientes y todavía defectivas, que sólo cumplen el requisito mínimo de seleccionar a los gobernantes mediante elecciones libres y limpias (electocracias). Son las que el politólogo Guillermo O’Donell denomina ‘democracias delegativas'”. Pues bien, incluso las democracias más transparentes no están libres de opacidad, sino que ésta cambia de naturaleza: "podría decirse, por tanto, que hay una opacidad residual o predemocrática, típica de los regímenes autoritarios y las democracias defectivas, y otra opacidad emergente o sobrevenida, que es compatible con las democracias de alta calidad" (ibídem: 46).

Y continúa su argumentación: “pero si la opacidad predemocrática está hecha de corrupción, fraude, abusos de poder e inseguridad jurídica, ¿cómo caracterizar a la opacidad específica de las democracias perfectamente constituidas? A este poder opaco irreductible a la democratización, que persiste más allá de la transición y la consolidación democráticas, podemos llamarlo 'poder elíptico' o 'poder en la sombra'. Ese poder en la sombra tiene que ver con las "materias reservadas, los secretos de Estado, los intereses nacionales, las agencias de seguridad nacional. Ese poder secreto es hoy un instrumento, entre otros, de los muchos que están en manos de las élites del poder que compiten y negocian por su control al margen de la ciudadanía. Y aquí es donde reside la verdadera fuente secreta del poder: en esas relaciones francas y confidenciales que mantienen de tú a tú los miembros de las élites dirigentes comprometidas en la ocupación del poder" (ibídem: 53). En los procesos políticos en relación al ejercicio opaco del poder, "nadie asume responsabilidades personales por su ejercicio, ni por tanto hay nadie a quien controlar o exigir que rinda cuentas por ello. Ésa es la tierra de nadie donde campan por sus respetos los podres opacos informales" (ibídem: 59).

En ese marco político, y en el actual contexto económico de la crisis iniciada en 2007, para Gil Calvo “por mucho que se recupere la estabilidad económica, como habrá de suceder más pronto o más tarde, la estabilidad política, por el contrario, no podrá recuperarse. Al menos en la periferia meridional de Europa, donde [...] se ha activado un ciclo de indignación y resistencia contra la política de austeridad. El desencadenante del ciclo fue la protesta contra los efectos económicos de esa política tan injusta como errónea. Pero al resistir contra la austeridad, la protesta derivó hacia el cuestionamiento del orden político e institucional, y no sólo del económico. Un orden político e institucional [...] que ha quedado seriamente desautorizado y deslegitimado a causa de sus evidentes disfunciones, frecuentemente fraudulentas, que hasta ahora permanecían ocultas en la opacidad" (ibídem: 223).

\subsection{La desigualdad y el consumidor fallido}

En opinión del sociólogo Zigmunt Bauman, catedrático emérito de Sociología en la Universidad de Varsovia y anteriormente profesor en las universidades de Leeds y Tel Aviv, en la London School of Economics, y premio Príncipe de Asturias 2010, en su libro ¿La riqueza de unos pocos nos beneficia a todos? (2014), la primera víctima de la enorme y creciente desigualdad existente en el mundo será la propia democracia. Citando estimaciones sobre la desigualdad en el mundo, concluye que "se necesitan pocos datos para confirmar de forma dramática que el sol se está poniendo sobre la 'era de los derechos’ en esta fase de la globalización. El 20 por ciento más rico de la población consume el 90 por ciento de los bienes producidos, mientras que el 20 por ciento más pobre consume el 1 por ciento. También se estima que las veinte personas más ricas del mundo tienen recursos iguales a los mil millones más pobres. El impacto del cambio que se está produciendo consiste en la degradación de la clase media al nivel del precariado" (ibídem: 20-21).

Bauman continúa señalando que "la desigualdad siempre se había justificado con el argumento de que los de arriba contribuían más a la economía, actuando como 'creadores de empleo'; pero entonces llegaron 2008 y 2009, y vimos cómo estos hombres que habían llevado a la economía al borde de la ruina se marcharon con cientos de millones de dólares" (ibídem: 25). Citando a otros autores -Lansey, Stiglitz, y Dorling- añade que "el dogma tan socorrido que afirma que el enriquecimiento de los de arriba acaba revirtiendo a la sociedad no es más que una mezcla de mentira intencionada y de forzada ceguera moral [...]. La lección más importante de los últimos treinta años reside en que en un modelo económico que permite a los miembros más ricos de una sociedad acumular una parte cada vez mayor del pastel acaba siendo destructiva. Ésta es una lección que, al parecer, todavía tenemos que aprender" (ibídem: 27-29).

Para Bauman, “la desregulación y la desmutualización [de las instituciones financieras y crediticias] resultó ser otro chollo para los que estaban a la cabeza de la industria financiera, y les proporcionó mayores salarios, comisiones y bonificaciones", mientras reducían todavía más los ya pequeños activos de millones de “'beneficiarios del crédito' que vivían y trabajaban en la economía real, pero que dependían de sus movimientos para mantener su medio de vida”. Para este sociólogo, "no hay beneficios en la codicia. No hay beneficios para nadie ni en ningún tipo de codicia. Es necesario que todos nosotros lo sepamos, lo comprendamos y lo aceptemos. Nosotros, que somos los que vivimos nuestras vidas en un mundo desregulado e individualizado, obsesionado con el crecimiento, el consumo, la competencia y el sálvese quien pueda" (ibídem: 103).

Bauman propone que seamos capaces de "desafiar el principio básico de la sociedad consumista, esto es, 
el axioma de que la búsqueda de la felicidad equivale a ir de compras, y de que la felicidad se debe buscar y se encontrará en los estantes de las tiendas [...]. Para los consumidores fallidos, la versión actualizada de los que no tienen, no comprar constituye el estigma lacerante de una vida incompleta, la prueba de su falta de entidad y de su sensación de que no sirven para nada. No sólo implica la ausencia de placer, sino también la ausencia de dignidad. De hecho implica la ausencia de sentido de la propia vida" (ibídem: 71-74).

El consumismo a ultranza, provocado en gran medida por nuestra decisión colectiva de perseguir la felicidad mediante el consumo, está en la base del desastre medioambiental que, en la medida en que se vaya produciendo, hará, en opinión de Bauman, más profundas las asimetrías, las desigualdades y las injusticias tanto entre generaciones como entre países.

\subsection{Límites actuales del proyecto europeo y sus riesgos}

Desde una perspectiva política, Martin Schulz, político socialdemócrata alemán, actual presidente del Parlamento Europeo, en su libro Europa: la última oportunidad (2013), nos presenta un análisis sobre el funcionamiento de la Unión Europea, sus evidentes limitaciones para actuar como sujeto político y económico, la insuficiencia de los mecanismos comunitarios actuales para responder a los problemas estructurales puestos en evidencia por la actual crisis, y aboga por el avance hacia la plena unión como necesidad si queremos preservar las características fundamentales del modelo europeo en el contexto internacional.

Dice Schulz, que "la crisis social en Europa hace dudar a muchas personas de la capacidad de acción de las instituciones y los políticos democráticos, y ha perjudicado enormemente la confianza en la UE. Esta crisis de confianza sólo puede superarse si distribuimos de forma más justa las cargas que genera la lucha contra la crisis económica" (ibídem: 97). Este político alemán, reconoce que "la UE está desacreditada a ojos de mucha gente. Se la considera desunida, antidemocrática, burocrática y neoliberal. He aquí una grave hipoteca para una organización que depende de la confianza de las personas". Tras reconocer los problemas que aquejan a nuestro marco europeo, señala a continuación los riesgos de su no existencia: básicamente, serían la vuelta a las monedas nacionales, a los controles fronterizos, a la desaparición de Europa como actor político global y el resurgir del nacionalismo obtuso. Cada uno de esos aspectos puede suponer muchos más problemas que soluciones (ibídem: 111 y ss.).

Europa, sin embargo, puede no fracasar. Para ello, en opinión de Schulz, debe trabajar en cuatro ámbitos si se quiere "desencadenar al gigante europeo": "fortalecimiento de la democracia, concreción de una política exterior europea digna de ese nombre, defensa de nuestro modelo de sociedad, contención del capitalismo depredador". En este sentido, apunta que "Europa será democrática o fracasará. Y a la inversa: sin Europa, fracasará nuestra democracia” (ibídem: 141). En un mundo en el que cada vez más ámbitos de la vida están globalizados, se agudiza la necesidad de cooperar en el campo de las relaciones transfronterizas. El cambio climático, la regulación de los mercados financieros, la lucha contra el hambre, la problemática de los refugiados y un control efectivo del armamento desbordan las capacidades de un solo Estado. Por eso, cada vez más decisiones se toman en foros internacionales" (ibídem).

Para Schulz, "el debate sobre la UE no puede centrarse en la cuestión de si volviendo al Estado-nación podemos recuperar nuestra soberanía. Eso no puede prosperar; la verdadera cuestión es saber si podemos recuperar, mediante la UE, la democracia en estos tiempos de globalización”. Junto a modificaciones en las instancias y estructuras comunitarias, habría que conseguir una "sociedad civil activa", sin la cual, la democracia no funciona (ibídem: 142). El actual presidente del Parlamento Europeo ve posible este fortalecimiento de la democracia europea. En opinión de Schulz, los pasos iniciados a partir de la Segunda Guerra Mundial hacia la superación de los Estadosnación, que han dado forma a la Unión Europa, deben continuar y reformularse para que sean verdaderamente respetuosos con los valores y principios que proclamamos defender. De nuevo, entronizar el poder centralizado de unos pocos Estados europeos no parece la mejor de las alternativas de futuro.

\section{Perspectiva económica}

Desde el análisis económico, Robert J. Shiller, catedrático de Economía en la Universidad de Yale (EE. UU.) y premio Nobel de Economía 2013, en su libro Las finanzas en una sociedad justa (2012) plantea que las sociedades avanzadas necesitan ineludiblemente de un sistema financiero, y que, por el bien común, debemos ser capaces de recuperarlo para que sea útil al conjunto de la ciudadanía.

\subsection{Hacia unas fianzas justas: regulación, progresividad, y filantropía}

Shiller plantea que más que demonizar el sistema financiero, lo que debemos hacer es reformarlo de manera que responda a las necesidades de la sociedad, a través de su democratización. Defiende un sistema financiero con las debidas regulaciones y una política fiscal progresiva que sea capaz, al mismo tiempo, de apoyar la filantropía como forma de coadyuvar al interés general.

Shiller manifiesta que "la aversión pública a la desigualdad está muy arraigada desde antiguo [...] [y que] es necesario que la gente sienta que la sociedad es básicamente justa con ella". Continúa 
señalando que "la injusticia de la distribución de los recursos en el capitalismo financiero es un tema de suma importancia”. La creciente desigualdad es, desde luego, una preocupación válida y que debe tenerse muy presente, pero, en su opinión, el capitalismo financiero no necesariamente provoca una distribución injusta de la riqueza: "las políticas públicas nos pueden permitir gozar de los beneficios de las fianzas modernas sin producir esta desigualdad" (ibídem: 308).

No obstante, como señala el economista norteamericano, "las sociedades tienen muchas dificultades para enfrentarse al problema de la desigualdad de una manera sistemática. El principio no ha sido nunca articulado expresando que cierto grado de desigualdad es, en cierta manera, bueno [...], pero que la sociedad tiene que poner sistemáticamente ciertos límites a ello" (ibídem: 321). Las medidas para corregir la desigualdad económica han de implementarse de manera global y articularse de forma clara en cuanto a conseguir cierto nivel adecuado de desigualdad: "tenemos que empezar a sopesar sistemas impositivos más complejos, fundados en la teoría de la gestión del riesgo y en la de la economía conductual. Nuestro sistema de impuestos sigue obstaculizado por ese viejo impulso por lo convencional y conocido. Pero teniendo en cuenta lo rápido que avanza la tecnología de la información [...], podemos introducir mucha más sutileza y capacidad de respuesta en el sistema fiscal para contribuir a obtener una sociedad mejor, en la que la gente sienta que la justicia económica básica está asegurada" (ibídem: 321).

Shiller señala que en Estados Unidos, en 2010, las donaciones por parte de individuos y organizaciones a causas colectivas (caritativas, religiosas, artísticas, científicas, medioambientales, educativas) representan sólo el 2,2\% de los ingresos nacionales. Los incentivos para orientar recursos privados a fines de interés general probablemente deban adaptarse a contextos políticos y culturas diferentes, pero pueden tener que ver con la personalización del reconocimiento, incluso a largo plazo, con el reconocimiento vía publicidad del apoyo realizado, o con el establecimiento de alguna forma de reciprocidad entre el donante y la entidad beneficiada, es decir, con la búsqueda de una "sensación de auténtica comunidad entre el donante y el receptor". También cabría graduar, dice, la tasa de deducción fiscal según el importe donado, y dar más incentivos fiscales por colaborar con organizaciones diseñadas para satisfacer necesidades nacionales concretas -desempleo, desigualdad-. En su opinión, "una redefinición adecuada de las leyes fiscales podría provocar el efecto de incentivar el comportamiento altruista" (ibídem: 323-328).

Shiller propone asimismo avanzar hacia la constitución de un nuevo tipo de organización que se podría denominar "participación corporativa sin afán de lucro". Estaría pensada para una función pública -como la gestión de un hospital-, pero en un sentido distinto. La participación sin afán de lucro recaudaría fondos emitiendo acciones, pero la compra de estas acciones constaría como una aportación caritativa respecto a las obligaciones tributarias. Vender acciones no tendría consecuencias fiscales siempre y cuando el rendimiento se donara a otras causas caritativas. Sólo si el accionista vendiera las acciones y consumiera el dinero de la venta tendría una penalización fiscal considerable. Permitir la inversión en este tipo de participaciones sin afán de lucro podría ser una buena manera de generar un mayor interés por causas públicas, sostiene (ibídem: 336).

El premio Nobel de Economía 2013 propone adoptar de manera colectiva la decisión deliberada de construir un capitalismo financiero con una base más amplia: "en el futuro deberemos estar alerta para evitar la concentración de poder económico, y deberemos trabajar para dispersar todavía más la propiedad del capital. Hacerlo de manera efectiva y eficiente, para que los resultados netos sean beneficiosos y no destruyan la productividad, y de manera que tengan en cuenta los nuevos desarrollos en el mundo de las finanzas y la tecnología de la información, requerirá una atención y una innovación continuadas" (ibídem: 357).

Según Schiller, es clave la mejora de la información disponible para la participación en el sistema financiero, de forma que se supere la situación actual en la que el ciudadano no cuenta con buena información y quienes deben asesorarles disfrutan de incentivos inadecuados para contarles lo que realmente necesi$\tan$ saber. Y añade, "hemos visto que son necesarias algunas intervenciones del Gobierno, incluyendo la redistribución de la riqueza a través de una tributación progresiva, y eso se podría realizar de manera más deliberada y juiciosa que la actual, sin levantar alarmas sobre la posibilidad de que la riqueza pudiera ser injustamente confiscada. Tiene que haber una red de seguridad para la sociedad, y ésta debe mejorarse y repensarse continuamente" (ibídem: 383 )

A su parecer, "la democratización de las finanzas va de la mano de su humanización [...]. En este sentido, es importante que las finanzas sean humanas, y que incorporen nuestro entendimiento cada vez más sofisticado de la mente humana en sus sistemas, modelos y predicciones. La ascensión de la economía conductual y de la neuroeconomía en las últimas décadas nos da una base para tal enfoque, para entender cómo piensa y actúa realmente la gente. Las personas no son de manera inherente y uniforme amables con sus vecinos, pero nuestras instituciones pueden cambiarse para gratificar el lado más bueno de la naturaleza humana" (ibídem: 384).

\subsection{El precariado: una nueva clase social}

Para Guy Standing, catedrático de Estudios del Desarrollo en la Universidad de Londres, doctor en Ciencias Económicas por la Universidad de Cambridge, miembro de la Academia de Ciencias Sociales del Reino Unido, y profesor en las universidades de Bath, Monash y de Melbourne, en su libro El precariado (2013), la crisis ha puesto de manifiesto una 
nueva clase social que venía gestándose desde hace décadas, el precariado. Una clase a la que, en su opinión, podríamos acabar perteneciendo todos los que no estamos en la élite del poder.

Para Standing, "durante la década de 1970, un grupo de economistas de acérrima inspiración ideológica captó la atención y los ánimos de los políticos anglosajones. La idea central de su modelo 'neoliberal' era que el crecimiento y el desarrollo dependían de la competitividad, por cuya maximización debía hacerse cuanto se pudiera, permitiendo que los principios del mercado impregnaran todos los aspectos de la vida". Y añade, "uno de sus temas preferidos era que los Gobiernos debían fomentar la flexibilidad del mercado laboral, lo que equivalía a un programa para transferir los riesgos y la inseguridad a los trabajadores y sus familias. El resultado ha sido la creación de un 'precariado' global, consistente en cientos de millones de personas sin un anclaje estable en su trabajo, que se está convirtiendo en una nueva clase peligrosa por su propensión a dar pábulo a voces extremistas 0 fanáticas, y a utilizar su voto y su dinero para ofrecer a esas voces una plataforma política que acreciente su influencia. El propio éxito de la agenda 'neoliberal', admitida en mayor o menor medida por Gobiernos de toda laya, ha generado un monstruo político incipiente. Hay que hacer algo antes de que ese monstruo cobre fuerza" (ibídem: 17).

El precariado es algo distinto de la clase obrera 0 del proletariado. Standing entiende que, en buena parte del mundo, las clases tradicionales siguen existiendo, pero, en su opinión, se pueden distinguir en las sociedades actuales siete grupos sociales (ibídem: 25 y ss.):

- La 'élite’, un pequeño número de ciudadanos globales espectacular y disparatadamente ricos.

- Los ‘altos directivos o ejecutivos', con empleo estable a tiempo completo. Aunque algunos aspiran a entrar algún día a formar parte de la élite, la mayoría se contentan con disfrutar de los privilegios de su clase, sus pensiones, sus vacaciones pagadas y su participación en los beneficios de las empresas.

- Más abajo, está un grupo más pequeño que denomina 'profitécnicos' - de 'profesionales' y 'técnicos'-, que disponen de habilidades cotizadas en el mercado que les permiten obtener elevados ingresos por contrato.

- Por debajo, en términos de ingresos, un cada vez menor número de trabajadores manuales, la esencia de la antigua 'clase obrera'. Los Estados del bienestar, así como los sistemas de regulación laboral, se construyeron pensando en ellos, pero los batallones de trabajadores industriales que vertebraban el movimiento obrero han mermado considerablemente y se ha perdido su conciencia de solidaridad social.

- Por debajo de estos cuatro grupos, está el 'precariado’, flanqueado por un ejército de desem- pleados, y un grupo deshilvanado de fracasados e inadaptados sociales que viven de los desechos de la sociedad.

Para Standing, el precariado consiste en personas carentes de alguna de las siete formas de seguridad relacionadas con el trabajo resumidas en el marco que los partidos socialdemócratas o laboristas, y que los sindicatos pretendían imponer tras la Segunda Guerra Mundial como programa de "ciudadanía industrial" para la clase obrera o el proletariado (ibídem: 30 y 31):

- Seguridad en el mercado laboral: oportunidades para obtener unos ingresos decentes. En el plano macroeconómico, esto se resume en el compromiso del Gobierno con el pleno empleo.

- Seguridad en el empleo: protección frente a despidos arbitrarios, regulaciones sobre la contratación y el despido.

- Seguridad en el puesto de trabajo: capacidad y facilidad para mantener un nicho en el empleo, oportunidades para la movilidad ascendente.

- Seguridad en el trabajo: protección frente a accidentes y enfermedades laborales, límites a la jornada de trabajo.

- Seguridad en la reproducción de las habilidades: oportunidades para mejorarlas mediante el aprendizaje y la formación.

- Seguridad en los ingresos: ingreso estable adecuado, indexación de salarios, Seguridad Social generalizada, fiscalidad progresiva para reducir la desigualdad.

- Seguridad en la representación: representación colectiva en el mercado laboral, sindicatos, derechos de huelga.

Standing advierte que "se defina como se defina, el precariado está lejos de ser homogéneo. El joven que sobrevive con empleos ocasionales, el cabeza de familia monoparental preocupado por la falta de estabilidad laboral y los ingresos ajustados, el mayor que necesita complementar sus ingresos para hacer frente a sus facturas médicas [...], todos ellos conforman el precariado" (ibídem: 35). En opinión de este economista inglés, el precariado experimenta además “las cuatro aes” (ibídem: 44):

- Aversión que brota de la frustración generada por el bloqueo de las posibilidades para llevar una vida fecunda.

- Anomía: "desviación o quiebra de las normas sociales", que genera una pasividad nacida de la desesperanza, que se ve, sin duda, intensificada por la perspectiva de ocupar empleos inanes y estancados.

- Ansiedad, vinculada a una inseguridad crónica asociada no sólo con sentirse al borde del abismo, sino también con el temor a perder lo poco que se posee. 
- Alienación con respecto a su empleo y trabajo, pues teme perder lo que tiene y se siente despechado, aunque normalmente sea incapaz de reaccionar. Su malestar se alimenta de miedo, y ésta es su principal motivación.

No es sólo una cuestión de empleo inseguro, de duración limitada y con una protección laboral insuficiente, aunque todo esto se ha generalizado. Standing define también el precariado como quedarse anclado en un estatus que no ofrece una posibilidad de carrera profesional, ningún sentido de identidad ocupacional segura y pocos derechos, si es que alguno, a las prestaciones estatales y empresariales que varias generaciones de quienes se veían a sí mismos como pertenecientes al proletariado industrial o a la Administración habían llegado a considerar como algo debido. Para el autor, "ésta es la realidad de un sistema que fomenta y departe líricamente sobre un modo de vida basado en la competitividad, la meritocracia y la flexibilidad. Una lección de la Ilustración es que el control del destino de cada ser humano debería estar en sus manos, y no en las de un dios o en las fuerzas naturales. Al precariado se le dice que debe responder a las fuerzas del mercado y ser infinitamente adaptable" (ibídem: 51).

Para este autor, deberíamos preocuparnos del precariado tanto por altruismo como por nuestro propio temor a caer en él, y por el riesgo de la deriva hacia los mensajes populistas y neofascistas, como ya se constata claramente en toda Europa, Estados Unidos y otros lugares. Por ello, se hace necesaria una política que responda a sus temores, inseguridades y aspiraciones. Y concluye, "el precariado no es ni víctima, ni villano, ni héroe; somos la mayoría de nosotros" (ibídem: 52, 86).

\subsection{La gran transformación}

El economista Trías de Bes, en su libro El gran cambio (2013), propone asumir que nos hallamos en medio de lo que denomina "la gran transformación”, fruto del fin de una larga etapa de expansión de Occidente y de una basculación de poder y riqueza hacia otras partes del mundo, y que las soluciones no pueden venir de las recetas clásicas de uno u otro signo. Se trataría de un problema de naturaleza evolutiva, que requeriría nuevos tratamientos para avanzar hacia una economía más viva, humana y solidaria. El liderazgo de los países emergentes y la irrupción de las nuevas tecnologías habrían convertido en obsoletos los modelos de negocio tradicionales: "las causas del gran cambio son la superglobalización prematura -irrupción de China y otras áreas geográficas en el comercio mundial, y reciente utilización masiva de las tecnologías de la información y de la comunicación-, el neoendeudamiento -excesivo de los países desarrollados que se nutren del ahorro extranjero, que se invierte de forma no productiva- y la neglitocracia corrupta -combinación de negligencia y corrupción tanto en la esfera pública como privada-. Elementos surgidos de una evolución inevitable: el derecho de los países emergentes a participar en el comercio internacional, y la evolución tecnológica, que han acelerado esta superglobalización. Identificadas estas causas, más evolutivas y, por tanto, no de raíz económica, el elenco de soluciones cambia radicalmente. El debate pasa de la austeridad o gasto, de más o menos déficit, de más o menos crédito, a otro debate bien distinto: a la legislación y homogeneización entre naciones. No a la regulación ni a la protección, sino a la legalización y nivelación de las reglas del juego entre países emergentes y occidentales, así como entre empresas del mundo físico y del mundo digital. Los problemas financieros y de endeudamiento son una consecuencia y no la raíz de esta gran depresión. Hay que abordarlos, por supuesto, pero sin solucionar lo esencial y medular, de poco servirá" (ibídem: 347).

Continúa señalando este economista que "el debate entre austeridad y gasto con el que los políticos nos tienen mareados es sólo una parte de la película, una dimensión del problema. La solución no es Keynes. Tampoco es el monetarismo. Nuestros problemas son también evolutivos, y no sólo económicos. Más Darwin y menos Keynes. Pero no en el sentido de que sobreviva el más fuerte y que se extingan los demás. No. Los seres humanos tenemos inteligencia. Y podemos lograr que los necesarios e inevitables cambios en el entorno no se traduzcan necesariamente en devastación". Vivimos una etapa de destrucción creativa, afirma, y "debemos y podemos actuar para que la creación, la innovación, los avances y la dinámica competitiva no se conviertan en destrucción despiadada o en una crisis que se vuelva contra la propia libertad de mercado, las democracias, el Estado del bienestar, el proyecto europeo y el comercio internacional. Se necesita una ciudadanía activa, que se implique para que el gran cambio, más allá de su impacto económico en forma de crisis, sirva para vivir en una sociedad mejor. Una sociedad más viva, más humana y más solidaria. Una sociedad con alma" (ibídem: 345-348).

\subsection{Hacia una economía del bien común}

Christian Felber, sociólogo y psicólogo austríaco, crítico de la actual globalización y fundador del movimiento Attac, plantea en su libro La economía del bien común (2012), una nueva definición de bien común, que incorpora factores tales como la dignidad humana, la solidaridad, la justicia, la sostenibilidad medioambiental y la democracia. Las empresas y las personas deberían orientar su trabajo hacia el logro del bien común entendido como algo ciertamente más amplio que el beneficio económico actualmente objeto de medida.

Para Christian Felber, "el marco de incentivos para los individuos activos en la economía tiene que cambiar radicalmente de la búsqueda de beneficios y la competencia a la búsqueda del bien común y la cooperación. El nuevo objetivo de las empresas es producir el mayor aporte posible al bienestar general. 
Hay que redefinir el éxito económico "de contabilizar los valores de cambio a contabilizar las utilidades sociales. Cambiar los testimonialmente débiles indicadores monetarios por testimonialmente fuertes indicadores no monetarios. Hay que avanzar hacia un ‘balance del bien común' que debería recoger cinco puntos que no son nada nuevo, porque ya se encuentran en la mayoría de las constituciones y de leyes fundamentales: dignidad humana, solidaridad, justicia, sostenibilidad medioambiental y democracia” (ibídem: 47).

El balance del bien común debe cumplir con ocho criterios (ibídem: 60):

- Compromiso: que la voluntariedad no conduce al fin lo han comprobado innumerables instrumentos de la responsabilidad corporativa.

- Totalidad: sería muy poco medir sólo los aspectos ecológicos o la calidad de los puestos de trabajo.

- Capacidad de medición: los resultados deben ser medibles, es decir, objetivamente valorados.

- Comparabilidad: todas las empresas deberían rendir cuentas con los mismos objetivos/ indicadores.

- Claridad: el balance no sólo debe ser comprensible para los consultores de empresas o los auditores del bien común. Debe serlo para todos: clientes, empleados y el público en general.

- De carácter público: el balance del bien común debe ser visible para todos y estar disponible por Internet.

- Auditoría externa: para evitar que las empresas se autoevalúen, como pasa con algunos instrumentos de responsabilidad corporativa.

- Consecuencias jurídicas: quien más haga por la sociedad debe, según el principio del beneficio justo, ser compensado por ello.

\section{5. "Ser más productivos para vivir mejor"}

Para el economista Luis Garicano, catedrático de Economía en la London School of Economics y doctor en Economía por la Universidad de Chicago, en su libro El dilema de España (2014), “España camina a trompicones, pero inexorablemente, por un sendero que conduce a perder los avances conseguidos por dos generaciones de españoles". Para evitarlo, se requiere avanzar hacia "una España moderna con instituciones fuertes e independientes, con un nivel de vida elevado, un sistema educativo abierto pero exigente, y con un Estado del bienestar sostenible. Un modelo que, en su misma esencia, está ligado a Europa. España, en fin, necesita a Europa”, pero aclara que "en la construcción europea no hay acuerdo posible sin confianza mutua, no hay rescate sin alianza" (ibídem: 12-13).

Para Garicano, “las sociedades más humanas están cerca de nosotros, en el norte de Europa. Allí, los que trabajan lo hacen menos horas y tienen más vacaciones, los que estudian hacen menos deberes en casa. Su elevada productividad permite que esto suceda a la vez que las empresas compiten internacionalmente con gran éxito”. A su parecer, "esta crisis nos ofrece una oportunidad de mover al país en esta dirección, hacia una sociedad más eficiente, pero a la vez más humana”. Aboga por una nueva relación entre los mercados y el Estado, con los siguientes cuatro parámetros: "en primer lugar, España necesita un regulador del mercado de productos predecible, creíble e independiente, no capturado por los grandes, que asegure que la competencia entre empresas sea real. Hay que salir de los oligopolios de amigos que se sientan a desayunar y se reparten los mercados [...]. En segundo término, es necesario reducir drásticamente las dificultades que sufren las empresas medianas y pequeñas para crecer. Es necesario que el terreno de juego no esté desnivelado en contra de los medianos y de los 'legales'. Las leyes laborales, las barreras de entrada, las licencias previas y las normas impositivas deben simplificarse todo lo posible para evitar dar ventajas al que vive en la economía sumergida o dispone de los gabinetes jurídicos para saltárselas. [...] Tercero, el mercado de trabajo, capital y el de productos tienen que ser mucho más dinámicos de lo que lo son en la actualidad. Es necesario asegurar que los recursos se reconducen hacia las actividades con mayor potencial productivo. Ello requiere cambios en la regulación bancaria, en el mercado de trabajo, y en los mercados de producto [...]. Y cuarto, el marco de relaciones entre el sector financiero y el poder público debe cambiar radicalmente. En este aspecto, sí que existe una esperanza clara de que esto suceda con la creación del supervisor único europeo y el traspaso de parte de las funciones supervisoras a Frankfurt, aunque aún no esté claro cómo se producirá en la práctica esta división de poderes" (ibídem: 116-117).

\subsection{Avanzar hacia otra visión del bien común}

Para Gaël Giraud, jesuita, director del Centro Nacional de Investigación Científica (CNRS) de Francia, miembro del Centro de Economía de La Sorbona y de la Escuela de Economía de París, en su libro La ilusión financiera (2013), una salida de la actual situación sería avanzar hacia la identificación de bienes comunes- ni privados, ni públicos-, entre los que él sitúa el trabajo, la tierra y el dinero. Los bienes comunes no lo son exclusivamente por su naturaleza, sino por la decisión política adoptada por la colectividad: "entre los recursos comunes se encuentran casi todos los 'bienes naturales' que hoy se ven amenazados, como el medio ambiente, el agua, los bosques, las superficies cultivables [...]. También las energías fósiles constituyen una enorme reserva de recursos que, por ahora, son objeto de un acaparamiento privado, pero que podría decidirse que se convirtieran en recursos comunes [...]. La liquidez y el crédito deben organizarse como bienes comunes" (ibídem: 130-133). 
Para este economista francés, la crisis europea no es, ante todo, una crisis de las finanzas públicas, sino una crisis de las finanzas desreguladas. Para salir de ese atolladero, la prioridad absoluta es encontrar el modo de hacer funcionar una máquina económica probablemente deflacionista durante decenios. Un camino al margen de la recesión es el de la transición ecológica, comenzando por el aislamiento térmico de los edificios y, posteriormente, por la movilidad. Esta transición ecológica requiere financiación, que debería venir del Banco Central Europeo, que debería actuar bajo mandato de una renovada autoridad política europea (ibídem: 18).

Para Giraud, el proyecto de construcción europea puede ser el escenario idóneo para hacer una lectura de los bienes comunes que supere la dicotomía privado-público, "habilitando unas reglas que no dependan exclusivamente ni del derecho a la propiedad privada, ni del derecho público de los Estados miembros" (ibídem: 152). Considera que "el bien común es resultado de la construcción de un marco reglamentario y de unas instituciones democráticas que organicen la reciprocidad [...]. Pero resulta que los tratados europeos han impreso al proyecto inicial una dirección que lo aleja del ideal de la construcción de 'comunes', institucionalizando, por el contrario, su privatización: la independencia del Banco Central Europeo; la iniciativa legislativa confiada a una Comisión Europea carente de todo mandato democrático; la desregulación de los mercados financieros; la confección de unas normas contables internacionales por parte de un organismo privado (IASB) preso de las instituciones financieras y los gabinetes de consejo; la unión bancaria; el tratado para la estabilidad, la coordinación y la gobernanza (TSCG); la prioridad concedida a la inflación (por encima de la lucha contra el paro, por ejemplo); la actual preponderancia del sector bancario sobre los propios Estados... todo ello revela a la perfección de qué se trata: al desposeer al poder público (nacional) de la gobernanza de esos bienes, las instituciones europeas no han convertido estos en bienes comunes, sino en bienes privados extraterritorializados" (ibídem: 153).

Giraud sostiene que "Europa debe situar entre los bienes comunes europeos las redes intraeuropeas (electricidad, gas, ferrocarril), así como la liquidez y el crédito: lo cual supone, de hecho, poner la regulación de los mercados y el mecanismo de creación de dinero al nivel europeo". Lo mismo cabe decir de otros ámbitos: "la fiscalidad de las empresas ya no puede seguir perteneciendo al estrecho campo de los Estados-nación. En el terreno laboral [...], podría exigir una revisión del derecho de las empresas que haga de ellas una comunidad de partes implicadas vinculadas por un proyecto económico. Esta revisión debe darse a nivel nacional, pero también a nivel europeo. Debería establecerse una autoridad confederal europea para la gestión de los bienes comunes monetarios y financieros en Europa” (ibídem: 164).

Para Giraud, avanzar hacia la identificación de bienes comunes y apostar por una transición ecológica en
Europa sería la manera de escapar de la actual crisis y de superar un escenario de crecimiento mínimo a largo plazo, al tiempo que la manera de evitar la definitiva consolidación de la quiebra social que se está produciendo.

\section{7. "Europa debe aportar justicia fiscal y voluntad política a la globalización”}

El economista francés Thomas Piketty, en su libro Le Capital au XXI e siècle, del que se apuntan aquí reseñas de prensa, ofrece un interesante análisis del crecimiento y rendimiento del capital en la historia. Como explica Antonio Quero (2014), "los datos [de Piketty] confirman que el rendimiento del capital ha sido sorprendentemente estable a lo largo del tiempo -en torno al $5 \%$-, mientras que la tasa de crecimiento ha oscilado entre el $1 \%$ y el $1,5 \%$. De esta, manera los patrimonios tienden a acumularse a un ritmo mayor que el efecto redistributivo del crecimiento por el aumento de la producción y los salarios, generándose desigualdades crecientes que, en los últimos años, han superado el pico de desigualdad que se produjo justo antes de la Primera Guerra Mundial". A diferencia de lo que ocurría en esas fechas, hoy, junto al $10 \%$ más rico, existe un $40 \%$ de la población que acumula un pequeño patrimonio, y un $50 \%$ que cobra un sueldo o una prestación, pero no acumula patrimonio y no deja casi nada a sus herederos. La reseña añade que "esa emergencia de la 'clase media patrimonial' es, para Piketty, la mayor transformación estructural del reparto de la riqueza en los países desarrollados. Con la ralentización del crecimiento y las rebajas fiscales de la revolución conservadora de la década de 1980, la clase alta patrimonial vuelve a emerger: el patrimonio del $10 \%$ más rico crece exponencialmente, mientras que el del $1 \%$ más rico lo hace estratosféricamente" (ibídem).

La perspectiva para el siglo XXI es de mantenimiento de tasas de crecimiento del orden del $1 \% 0$ 1,5\% y de rendimientos del capital en torno al $5 \%$. La implicación evidente es que el reparto de la riqueza acentuaría su senda divergente hasta alcanzar cotas social y democráticamente inaceptables. El análisis frío y objetivo de la ingente cantidad de información que hace Piketty en su libro ofrece una perspectiva para el siglo XXI poco alentadora, con una economía mundial instalada, desde hace treinta años, en una senda firme de acumulación cada vez mayor de riqueza en lo alto de la pirámide. Ante ello, este economista francés plantea propuestas concretas para atenuar 0 corregir dicha evolución. La principal es instaurar un impuesto mundial progresivo sobre el capital, tanto de los activos inmobiliarios como mobiliarios. Piketty no se hace ilusiones sobre la viabilidad política de su propuesta, aunque argumenta convincentemente sobre su viabilidad en el seno de la Unión Europea si existiera suficiente voluntad política. Considera su propuesta como "utopía útil" en el sentido de que obliga a cualquier otra solución a medirse con respecto al ideal teórico que constituye dicho impuesto. También señala los beneficios que comportaría, más 
allá de la recaudación, la cooperación fiscal internacional necesaria para implantarla.

Propone asimismo establecer, en los países de la zona euro, un impuesto común sobre los beneficios de las empresas. Cada país podría seguir fijando su impuesto de sociedades sobre esa base común, con un índice mínimo del orden del $20 \%$, y retener un impuesto adicional federal del orden del $10 \%$. Con ello, el presupuesto de la zona euro pasaría del actual 0,5\% al $1 \%$ del PIB agregado, y así, la zona euro podría impulsar el relanzamiento y la inversión, especialmente en medio ambiente, infraestructuras y formación: "Europa debe aportar justicia fiscal y voluntad política a la globalización” (cit. en GallegoDíaz, 2014).

Piketty ha apoyado también el Manifiesto por la Unión Política del Euro (2014), que contiene recomendaciones prácticas para salir del atolladero en el que se encuentra la zona euro, y apuesta por propuestas económicas y políticas necesariamente vinculadas, tales como reconocer la disfuncionalidad de una moneda común y dieciocho deudas públicas diferentes, la necesidad de mutualización parcial de las deudas europeas, y de avanzar hacia un Parlamento Europeo con verdadero poder político, especialmente en la zona euro.

\section{Resumen y conclusiones}

En opinión de los autores citados, nos encontraríamos en un tiempo de cambios profundos que recibe diversas denominaciones -'crisis sistémica', 'gran transformación', 'cambio de era'-, en el que las cosas no son como fueron, y en el que las recetas clásicas de uno u otro signo resultarían inadecuadas o insuficientes, requiriéndose nuevos enfoques e instrumentos para identificar un camino de mejora y progreso para el conjunto de la humanidad. La 'gran transformación' que afecta a todos los ámbitos de la vida se produce en un momento en el que, como parte del mismo fenómeno, que algunos autores denominan 'de destrucción creativa', se dan dos fenómenos paralelos:

- Por un lado, las formas de poder conocidas en la historia reciente experimentan significativas modificaciones, pudiendo llegar a hablarse de una cierta dilución del poder, pues, a pesar de su fundamental persistencia, éste se ha modificado, haciendo que, de alguna manera, sea menor que antaño, y más complejos los mecanismos colectivos para adoptar decisiones que afecten a la globalidad.

- Por otro lado y, de nuevo como parte de la gran transformación, vivimos en una etapa en la que la ciudadanía, que cada vez sabe más y exige más, experimenta una creciente desafección de la política, al no ver sus necesidades recogidas en la agenda política, lo que puede ofrecer, como alternativas fáciles, la vuelta a diversas formas de populismo y neofascismo, que pueden poner en riesgo los equilibrios alcanzados históricamente por las sociedades más avanzadas y democráticas.

La encrucijada en la que se encuentra la Unión Europea es una variable que se debe intentar despejar desde el interés de las mayorías sociales, fortaleciendo la democracia y modificando el entramado institucional desde la base hasta la cumbre, de manera que la política -el interés de la mayoríapueda dirigir el enorme potencial de la Unión.

Los planteamientos recogidos en la declaración Por una economía al servicio de las personas (2014), promovida, entre otros, por profesores universitarios del País Vasco, podrían constituir una interesante referencia para resolver la actual situación, al plantear, entre otras propuestas, equidad al tiempo que eficiencia, transparencia, y una Europa equilibrada social y territorialmente que sea capaz de defender la democracia y la cohesión social.

A pesar de la reciente salida de la pobreza de un número importante de ciudadanos en el mundo, debido al desarrollo económico en las países emergentes, son demasiadas las personas que no han alcanzado un estándar de vida suficientemente digno, y muchas las que lo están perdiendo, corren el riesgo de hacerlo o anticipan un deterioro de expectativas para sus hijos, la próxima generación. Como dice el historiador Josep Fontana en su libro El futuro es un país extraño (2013), "el de comienzos del siglo XXI es un mundo con muchas frustraciones y mucho rencor acumulados, que pueden prender en el momento más inesperado. La capacidad de tolerar el sufrimiento no es ilimitada [...]. La tarea más necesaria a que debemos enfrentarnos es la de inventar un mundo nuevo que pueda ir reemplazando al actual, que tiene sus horas contadas" (ibídem: 153). Y añade: "se trata de reinventar un nuevo futuro, todavía un país desconocido, una vez arruinadas las posibilidades de realizar el viejo: el que tuvo su origen en las anticipaciones de la Ilustración y alentó nuestras esperanzas hasta el fin de las tres décadas expansivas que siguieron al término de la Segunda Guerra Mundial” (ibídem: 20).

Dada la situación de la economía y de la política a escala mundial, es necesario y urgente un acuerdo básico entre distintas visiones para superar el actual estado de cosas y proponer un horizonte más esperanzador para el conjunto de la humanidad. Un acuerdo para avanzar hacia una nueva comprensión del bien común que debería incorporar, al menos, los siguientes elementos:

- Revisar la forma en que se adoptan las decisiones políticas, estableciendo mecanismos que hagan posible la participación de la ciudadanía y el logro de acuerdos, especialmente respecto a los bienes públicos globales.

- Aunar eficacia económica con equidad en la organización de la vida económica; regular en modo suficiente los mercados y, en particular, el sistema financiero. 
- Conseguir tamaños adecuados de los Estados, que los hagan capaces de intervenir eficazmente en el logro y mantenimiento del bienestar colectivo.

- Acordar políticas fiscales progresivas que aporten recursos a las administraciones públicas, abriendo, al mismo tiempo, espacios a la participación económica privada en objetivos de interés general.

- Priorizar el empleo digno y la lucha contra la desigualdad.

- Avanzar hacia la legalización y nivelación de las reglas de juego entre países desarrollados y emergentes.

En fin, habría que alcanzar un acuerdo que avance hacia una definición consensuada del bien común que tenga por objeto el logro de sociedades cohesionadas en economías avanzadas y en aquellas que tienen la legítima aspiración de llegar a serlo.

Para Trías de Bes, "da la sensación de que todavía los políticos piensan que esto es transitorio y que se trata de apretar los dientes unos años y gestionar el corto plazo". Al contrario, según este economista, "esto no es una crisis de corto plazo; esto es un cambio de era. $Y$ estamos obligados a reinventarlo casi todo, desde cómo nos organizamos hasta cómo gestionamos lo publico, cómo emprendemos, cómo pagamos impuestos, cómo los gastamos, cómo repartimos funciones, cómo educamos, cómo invertimos, o cómo prestamos" (2013: 171).

Para Moisés Naím, "restablecer la confianza, reinventar los partidos, encontrar nuevas vías para que los ciudadanos corrientes puedan participar de verdad en el proceso político, crear nuevos mecanismos de gobernanza real, limitar las peores consecuencias de los controles y contrapesos y, al mismo tiempo, evitar la concentración excesiva del poder y aumentar la capacidad de los países de abordar conjuntamente los problemas globales deberían ser los objetivos políticos fundamentales de nuestra época" (2013: 353).

Para Thomas Piketty, hay que establecer a escala mundial un impuesto progresivo sobre el capital, para corregir la tendencia creciente a una mayor desigualdad -que puede llegar a ser insostenible desde un punto de vista social y democrático-, y en Europa, avanzar hacia una unión política en la zona euro, estableciendo instrumentos de política fiscal comunes, dotando a la Unión de mayor capacidad presupuestaria para impulsar el relanzamiento y la inversión, especialmente en medio ambiente, infraestructuras y formación.

Por último, para Gaël Giraud es clave avanzar hacia una nueva interpretación de los bienes comunes e iniciar urgentemente la transición ecológica en Europa. En su opinión, de los planteamientos que dicen que la justicia social sería ineficaz y tendría que ser conquistada a expensas de la eficacia, habría que pasar a un discurso compartido entre la derecha y la izquierda "en el lugar en el que ambas sensibilidades colocan el cursor entre equidad y eficacia". Y, he aquí la sorpresa, "en casi todas la situaciones que nos interesan, la lógica de la reciprocidad permite superar en eficacia a la de la búsqueda del interés egoísta de cada cual. La reciprocidad no es, pues, únicamente cuestión de equidad social, sino también de eficacia económica" (2013: 156).

Concluyendo, en la era de la gran transformación y de la progresiva dilución del poder, necesitamos avanzar hacia una comprensión acordada del bien común, para lo que deberíamos aplicar en la economía y en la política, de manera innovadora, principios éticos tradicionales. 


\section{Bibliografía referenciada}

(2014): Manifiesto por la Unión Política del Euro [rhttp:// pouruneunionpolitiquedeleuro.eu/es/>].

(2014): Por una economía al servicio de las personas [«http://www.pertsonenekonomia.info〉].

BAUMAN, Z. (2014): ¿La riqueza de unos pocos nos beneficia a todos?, Barcelona, Paidós.

FELBER, C. (2012): La economía del bien común, Barcelona, Ediciones Deusto.

FONTANA, J. (2013): El futuro es un país extraño, Barcelona, Ediciones Pasado \& Presente.

GALLEGO-DÍAZ, S. (2014): "Los futuros posibles se pueden elegir", El País, 20-4-2014 [rhttp://elpais.com/elpais/2014/04/16/ opinion/1397665817_626824.html/].

GARICANO, L. (2014): El dilema de España, Barcelona, Península.
GIL CALVO, E. (2013): Los poderes opacos: austeridad y resistencia, Madrid, Alianza Editorial.

GIRAUD, G. (2013): La ilusión financiera, Maliaño, Sal Terrae. MAÍM, M. (2013): El fin del poder, Barcelona, Debate.

QUERO, A. (2014): “El capital en el siglo XXI”, El Diario. es, 2-2-2014 [<http://www.eldiario.es/ piedrasdepapel/Capitalismo-desigualdadsiglo_XXI_6_224737531.html)].

SCHULZ, M. (2013): Europa: la última oportunidad, Barcelona, RBA.

SHILLER, R. J. (2012): Las finanzas en una sociedad justa, Barcelona, Ediciones Deusto.

STANDING, G. (2013): El precariado, Barcelona, Ediciones Pasado \& Presente.

TRÍAS DE BES, F. (2013): El gran cambio, Madrid, Temas de Hoy. 
